Abstract

\title{
A Lipoaminopeptaibol Secreted by Alkalophilic Fungus Emericellopsis alkalina Demonstrates a Strong Cytotoxic Effect against Tumor Cell Lines ${ }^{\dagger}$
}

\author{
Eugene Rogozhin $1,2,3, *$ and Vera Sadykova ${ }^{2}$ \\ 1 Shemyakin and Ovchinnikov Institute of Bioorganic Chemistry of the Russian Academy of Sciences, \\ Moscow 117997, Russia \\ 2 Gause Institute of New Antibiotics, Moscow 119021, Russia \\ 3 Institute of Ecological and Agricultural Biology (XBio), Tyumen State University, Tyumen 625003, Russia \\ * Correspondence: rea21@list.ru \\ + Presented at the 2nd Molecules Medicinal Chemistry Symposium (MMCS): Facing Novel Challenges in \\ Drug Discovery, Barcelona, Spain, 15-17 May 2019.
}

Published: 6 August 2019

\begin{abstract}
Soil fungi are known to produce and secrete antibiotics with a strong antimicrobial effect towards eukaryotic organisms. In many occasions, these compounds belong to peptides that are products of non-ribosomal biosynthesis and are called peptaibols. Many peptaibols are cytotoxic and some of them suppress tumor cell lines much better than normal cells by inducing calciummediated apoptosis. The main antimicrobial lipoaminopeptaibol-emericellipsin A-isolated from the fungus Emericellopsis alkalina strain VKPM F-1428, which demonstrates promising antifungal activity against different fungal taxons, has been found to exhibit selective cytotoxic activity against HepG2 and Hela cell lines (EC50 2.8 and $0.5 \mu \mathrm{M}$, respectively) in MTT assays in vitro. This result corresponds to the standard antitumor antibiotic doxorubicin, which has an EC 50 value of $440 \mathrm{nM}$. In a fibroblast toxicity test, emericellipsin A exhibited less cytotoxic activity than doxorubicin (EC50 14 and $0.34 \mu \mathrm{M}$, respectively). Therefore, it is less toxic to normal cells than doxirubicin ( 40 times), but it yields a more potent cytotoxic effect on tumor cell lines. That is why emericellipsin A can be considered for future more detailed investigations to be an effective antitumor substance.
\end{abstract}

Keywords: peptaibol; emericellipsin A; Emericellopsis alkalina; cytotoxic properties

Funding: This work is supported by the Russian Science Foundation (grant № 18-74-10073).

(C) 2019 by the authors. Licensee MDPI, Basel, Switzerland. This article is an open access article distributed under the terms and conditions of the Creative Commons Attribution (CC BY) license (http://creativecommons.org/licenses/by/4.0/). 